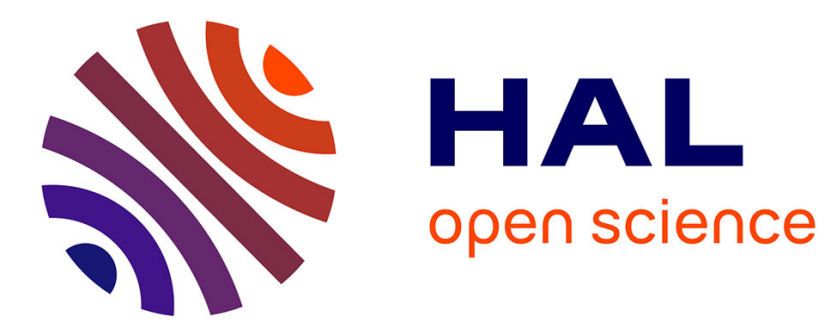

\title{
Diverse Scope Coordination in Design Management
}

Shuichi Fukuda

\section{To cite this version:}

Shuichi Fukuda. Diverse Scope Coordination in Design Management. 13th IFIP International Conference on Product Lifecycle Management (PLM), Jul 2016, Columbia, SC, United States. pp.559-566, 10.1007/978-3-319-54660-5_50. hal-01699726

\section{HAL Id: hal-01699726 \\ https://hal.inria.fr/hal-01699726}

Submitted on 2 Feb 2018

HAL is a multi-disciplinary open access archive for the deposit and dissemination of scientific research documents, whether they are published or not. The documents may come from teaching and research institutions in France or abroad, or from public or private research centers.
L'archive ouverte pluridisciplinaire $\mathbf{H A L}$, est destinée au dépôt et à la diffusion de documents scientifiques de niveau recherche, publiés ou non, émanant des établissements d'enseignement et de recherche français ou étrangers, des laboratoires publics ou privés. 


\title{
Diverse Scope Coordination in Design Management
}

\author{
Shuichi Fukuda ${ }^{1}$, \\ ${ }^{1}$ System Design and Management, Keio University, Yokohama, Japan \\ shufukuda@gmail.com
}

\begin{abstract}
This is a position paper to share our experience how Lazy Evaluation approach in AI is useful for team decision making with members with diverse knowledge and experience from many different fields. For example, Industrie 4.0 is a German proposal of a new framework to team up SMEs in order to cope with the frequent and extensive changes today. Until recently, we could fight with 11 best players, but today we need to fight with best 11. If the situations do not change then best players in each position can form a good team and win. But just as soccer demonstrates, such fixed formation does not work anymore. All players have to changes their roles flexibly and adaptively in response to the change. But unlike soccer where a goal is very clear, engineering teams need to determine a common goal first of all. But the greatest difficulty is members have different knowledge and experience, especially so when members come from different fields. Thus, how we can coordinate their diverse scopes and come up with an identical scope which satisfy all members and which leads to fruitful collaboration is a big challenge. This paper describes how Lazy Evaluation is effective for negotiation among members with diverse knowledge and experience and for coming up with an identical goal toward fruitful collaboration.
\end{abstract}

Keywords: Design Management, Diverse Members, Scope Coordination, Lazy Evaluation, Satisficing.

\section{Design Scope Coordination}

Although there are many papers on design management, there are very few on design scope coordination. For example, in project management, work scope and product scope are taken up. Work scope is about how to run the project and product scope is what product to produce. Although there are detailed discussion about how these scopes should be executed, how the scope should be framed is not well discussed.

But most important issue is how we frame our scope. This is essentially the same problem as has been discussed in AI research field as the Frame Problem. "The Frame Problem is the challenge of representing the effects of action in logic without having to represent explicitly a large number of intuitively obvious non-effects in AI, but it can be regarded as a more general problem of How do we account for apparent ability 
to make decisions on the basis only of what is relevant to an ongoing situation without having explicitly to consider all that is not relevant?" [1].

Design scope coordination is a typical example of the Frame Problem. With the progress of engineering and with the quickly spreading diversification and personalization, engineering problems cannot be solved without involvement of many experts from many different fields. Thus, what becomes important, but is not taken up for discussion is how we fill up their differences and reach a final goal acceptable to all members involved.

In project management, PMBOK [2] plays an important role, but it does not describe these diverse "common senses". And when they discuss parameters such as functional, design, etc., the scope is already fixed. The most important issue how we can frame our strategic scope is not discussed enough.

Pre-stage of Project Management becomes, however, increasingly important especially in PLM, because PLM requires very broad knowledge and experience across many different fields as it requires not only knowledge about design, manufacture, but also operation, i.e., it covers a very broad context.

\section{Increasing Importance of Decision Making}

This issue boils down to the problem of how we make decisions. Most of the research on project management and related works are dealing with the problems after a decision is made. But decision making in cases which relate to a wide variety of fields and broad contexts must be accepted by all members concerned who come from diverse fields. Of course, all members do not share the same knowledge and experience. They have their own views and even the same knowledge is used differently from field to field. So scope coordination for decision making is increasing its importance. Then, how can we overcome such difficulties and make appropriate decisions in an age of increasing diversification and personalization?

\section{Lazy Evaluation}

If we look back and consider how we make decisions, we soon realize that we do not make decisions all at once. The more difficult the problem is, the more time or stages we take to come up with the final decision. In other words, the larger problem space is, the more time or stages we need to fix our scope. In fact, when the problem space is very large, we cannot make decisions rationally due to such problems of combinatorial explosion, computational complexity, etc., and we have to look for satisficing as Herbert Simon pointed out [3]. Interestingly enough, another economist John Keynes pointed out economic agents make decisions rationally for short term expectations, but when it comes to long term, they rely on their confidence [4]. Thus, how we can let members feel satisfied and how they can agree upon the final goal with confidence is most crucial in team decision making with members from diverse fields.

The difficulty of decision making in a problem relating to diverse fields is scopes are different from member to member so that they are not identical. Of course, 
members do their best to increase the overlapping common area, but no matter how much efforts they may pay to increase it, there still remains areas which are not covered by all members (Fig.1). The most important thing is how we can find a common area, or intersection if we use set theory term, among all members involved with satisfaction and with confidence.

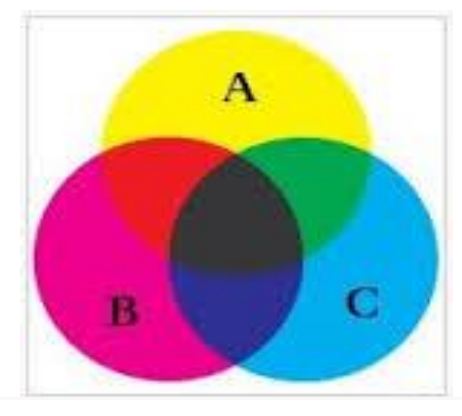

Fig.1. Intersection

If this common area or intersection can be found easily, then there is no problem. There might be slight differences, for example, regarding the definition of parameters, etc., among diverse members, but such small discrepancies can be easily solved if detailed discussion is made. Although it may take time, it is essentially not different from one time decision making.

Such one time decision making can be done when the problem is not so much complicated or large. Essentially rational approaches can be applied and the problem will be solved.

But when the problem relates to a wide variety of fields, such rational approaches cannot be applied and we have to introduce multi-stage decision making and repeat the process of convincing members that the line of reasoning is adequate. If the problem is small and simple, members can understand the line of reasoning easily and although it may take time, we can reach the common goal.

What makes multi-stage decision making difficult which relates to a wide variety of fields is there are issues which some of the members cannot understand at some stages, because the lines of reasoning vary from field to field. These members have to wait until the reasoning comes to the stage when they understand how the problem is going to be solved. When the reasoning comes to the stage they can understand, they can express their views and opinions and ask for revision, etc., based on their own knowledge and experience.

Then, how can we deal with this problem of multi-stage decision making in a situation where the problem is related to many diverse fields?

Lazy evaluation is the answer to this problem. We postpone our decision until later stage when we can make a decision. When the discussion comes to the stage you understand, then you can express your opinion and demand, if necessary, to change the conclusion which is obtained through the previous stages or give advice to 
improve the conclusion, based on your own field. And in the worst case, when you cannot understand the whole process, the constraints must be relaxed and repeat such trial and error approach from the first until every member understands the line of reasoning and can agree upon the final decision. This way, the final conclusion is reached by unanimous agreement of all members (Fig.2).

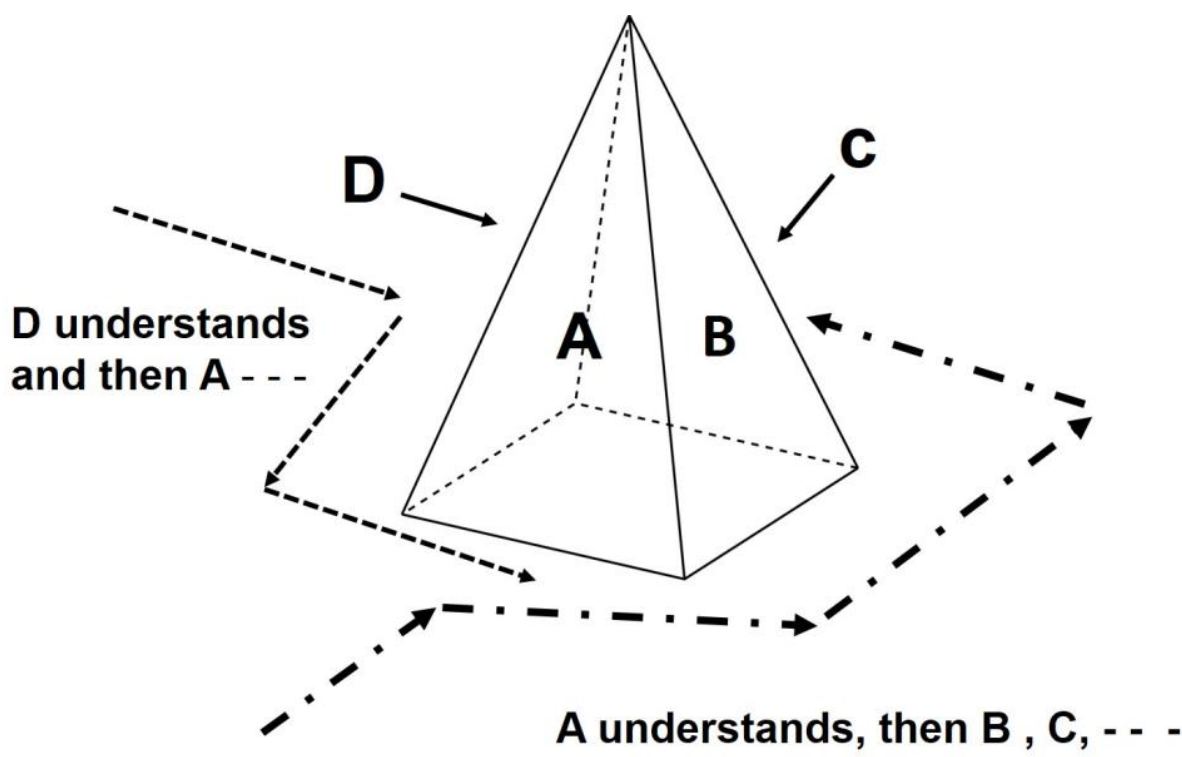

Fig.2. Illustrative Explanation of Lazy Evaluation Used for Team Decision Making with Diverse Members with Diverse Backgrounds

In other words, the common area or interaction varies with how the discussion goes on. In rational approaches, the common area or interaction does not change. But in the case of multi-stage decision making with diverse members, we have to note that the common area or the common goal varies from case to case. If some members are taking the initiative, the goal would reflect their knowledge and experience more.

Thus multi-stage decision making in a team with diverse members from diverse backgrounds is nothing other than negotiation. We have to remember negotiation comes first before collaboration. In other words, when the problem cannot be solved rationally, we have to resort to negotiation among members from diverse fields. But how we can negotiate to arrive at the common goal by coordinating the scope is not well discussed. 
Thus, this final solution may not be the optimum in the strict sense, but it is a satisficing solution. Herbert Simon pointed out that if the number of variables is too many, we cannot find the optimum mathematically due to such a problem of computational complexity, etc. so that we have to satisfy ourselves with the notion of satisficing. The term Satisficing is a combination of satisfy and suffice and it means satisfy enough [3].

To understand Simon's idea better, let us consider global optimization. Although the optimum can be obtained rationally if it is local optimization, we cannot obtain such a mathematically accurate optimum, when it comes to global optimization. Take Simulated Annealing for example. We repeat searching many times to reach an optimum, but it is nothing other than to regard the highest (or the lowest) one as the optimum, because we have repeated so many searches. There is no mathematical guarantee that it is the highest. We only believe or would like to believe it is the highest because we tried so many times. Thus, global optimization just makes us emotionally satisfied. It is nothing other than satisficing.

Lazy Evaluation is a method originally proposed in programming language theory. The primary reason why it was invented was to reduce the running time and to increase performance, because it avoids repeated evaluation. But the point which this paper emphasizes is very much different. This approach works very well for negotiation for decision making for a team with members of many different backgrounds

Lazy evaluation permits very flexible and adaptable line of reasoning. Thus, it provides us with a tool to reach emotionally satisfied conclusions. Again, this approach is useful to convince every member of a team with different backgrounds that the line of reasoning is adequate and their knowledge and experience are duly reflected in the final conclusion so that they accept it with enough satisfaction. But we have to remember that nobody sees or understands the whole picture. So this approach is completely different from an approach to construct a meta-level knowledge and experience representation for decision making.

\section{System to Produce Welding Procedure Specification}

This chapter describes our past experience of producing a legal document called Welding Procedure Specification. We formed a consortium with about 12 industry members with the leadership of Welding Research Institute, Osaka University. The members include Nippon Steel, Mitsubishi Heavy Industry, Kawasaki Heavy Industry, Kobe Steel, Toyo Engineering, Shimizu Corporation, IHI, Shin-Meiwa, etc. Their field are heavy industries, shipbuilding, airplanes, automobiles, etc.

As is well known, welding requires a wide variety of knowledge and experience such as material, electrical, mechanical, etc. and its application areas are also diverse such as civil, architectural, transportations, etc. But to carry out welding, there are legal rules which require us to specify how welding will be done.

These rules about welding is different from country to country. American Welding Society introduce such concepts as welding of box-type components and set down legal rules to apply to welding of boxes. Such boxes are used for containers, and used 
as components in ships, truck, etc. So such legal rules based on structural modules can be applied in a straightforward manner.

But in Japan, welding rules are set based upon the concept of weldline. Thus, we have to work out rules for each case because weldments vary widely from structure to structure and from product to product. Japanese rules pay attention only to welding, and they do not take into consideration such constraints as structures, etc. So industries have to form Welding Procedure Specification (WPS) to demonstrate that the welding they are going to perform follows the legal rules of Japanese welding rules and in addition that their way is reasonable enough from other respects.

This process of producing WPS, however, used to be a world of the rule of thumb. When industries worked in their own fields and their products and services were not so much diversified as they are today, the rule of thumb worked well.

But when shipping business was very bad in Japan, their welding department attempted to secure employment of their welders by receiving orders from other industries such as construction, etc. But they could not. This is because they relied too much on their rule of thumb and this rule does not work in other industries. Such failures prompted them to introduce a more rational and versatile approach.

To respond to their request, we developed an AI-based system which adopts Lazy Evaluation and Constraint Management [5], [6], [7].

The system itself is not special in the sense of programming. But we paid out chief attention to how members will feel satisfied with the flow of reasoning. We constructed a knowledge and experience representation, by noting that members with adjacent area can communicate easily. By putting together such member to member pieces together, we come up with the final representation as shown in Fig.3. Then, we adopted Lazy Evaluation technique to utilize this representation. 

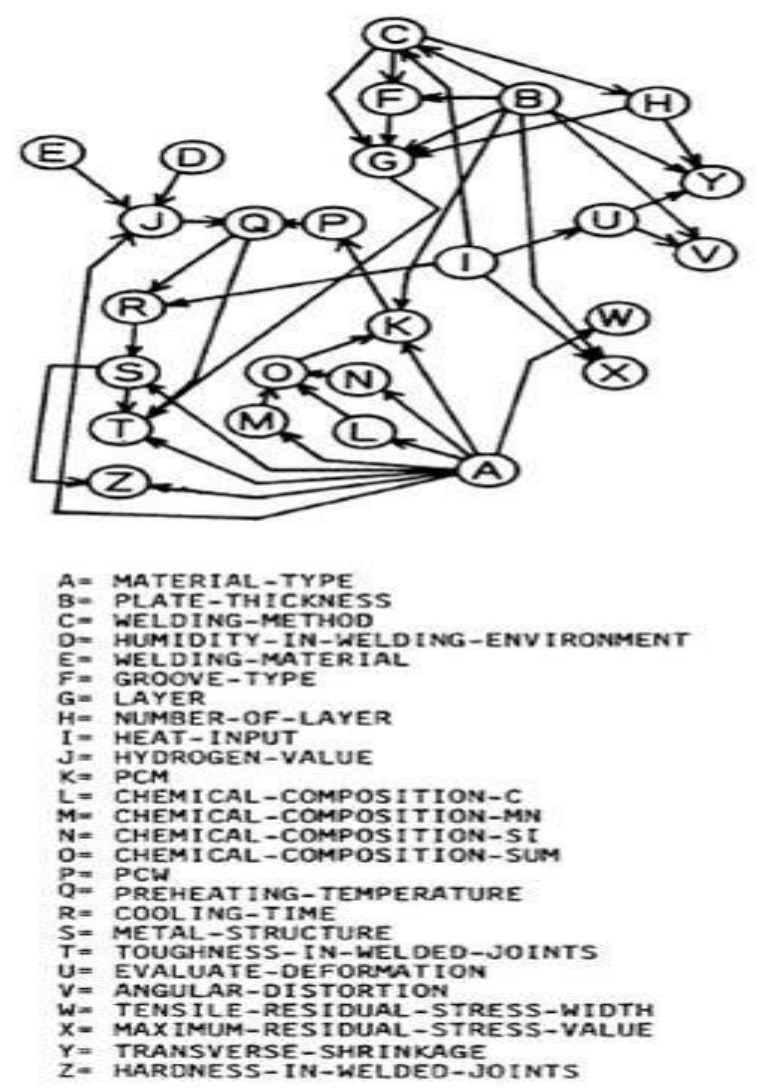

Fig. 3. Knowledge and Experience Representation for Welding Procedure Specification

This system met industry needs and it was adopted by many major Japanese industries. Their fields include Shipbuilding, Building, Construction, Machinery, etc., although each industry customized it to meet their needs. But the basic structure is the same. Their system introduced Lazy Evaluation. They are being used today, although they are updated of course.

This demonstrates how such a system was needed and desired by industries. But at that time, industries were working in their own fields and there were few problems which required such a wide variety of knowledge and experience as in welding, so they could manage to solve the difficulty by accumulating experience.

But with quickly increasing diversification, the walls between industries are falling quickly apart and industries have to collaborate across many different areas. Thus, the need for more adaptable and flexible decision making tools are increasing rapidly.

Although the time we developed the system and the time Japanese industries started to use our system in welding was long time ago, before such diversification as we see today started, such needs were present in such a multi-expertise field as 
welding because it relates to many different fields so that collaborative decision making is called for.

The technique or programming of Lazy Evaluation can be easily found in AI literatures. What this paper emphasizes is that it can be used very effective for another application, i.e., negotiation before collaboration, although it was originally developed for programming efficiency.

The need for such a system for supporting decision making among members from widely different fields is quickly increasing, such as in Industrie 4.0 [8]. Although the system we developed was only for welding, the basic framework certainly works for other applications. As the number of variables are rapidly increasing and the backgrounds of participating members are quickly diversifying, such an approach to reach a strategic goal acceptable by all members is increasing its importance.

\section{Summary}

Increasing diversification and personalization call for collaboration among many members from many different fields. And the more diversified the requirements become, the more difficult it becomes to reach a common strategic goal acceptable to all members, because knowledge and experience are different from field to field and sometimes the same knowledge is used in a different way.

Therefore, how we can coordinate their different scopes and come up with an identical scope is a great challenge and its solution is strongly called for. In other words, negotiation is needed for satisficing and convincing collaboration.

This paper points out by sharing our experience in welding that Lazy Evaluation, which is one of the AI techniques for computer processing efficiency, can be used in a very different way. It is very effective for negotiation to come up with an identical scope and to determine a common goal which is satisficing and convincing to all members.

As Industrie 4.0 indicates, our world is moving more toward best 11 from 11 best, as American football coach Knuth Rockne pointed out. It is no more the time if we assemble 11 best players, we can win. We have to consider how we can utilize the presently available resources to the maximum. Rockne demonstrated his belief by bringing University of Notre Dame from the bottom to the top. This can also be observed in soccer. Situations change so frequently and widely in today's soccer so that it becomes increasingly important how we can form a strategy flexibly and adaptively to the changes.

Another important point is as everything is speeding up these days, we do not have enough time to develop new technology to cope with the changing situations. Thus, what we need now is "Do what you can, with what you have, where you are" as Theodore Roosevelt said. We have to utilize the current resources to the maximum in order to achieve the goal. We have to form a well working team, but with the available members.

Lazy Evaluation can be used, in spite of its misleading name, to arrive at a common goal shared by all member quickly and to satisfice them all. Although it was originally a technique to facilitate processing speed on a computer, but what this paper emphasizes is that it can be used for facilitating negotiation before collaboration. 


\section{References}

1. Stanford Encyclopedia of Philosophy, http://plato.stanford.edu/entries/frameproblem (visited on April 14, 2016)

2. A Guide to the Project Management Body of Knowledge (PMBOK Guide), Fourth Edition,

http://www.works.gov.bh/English/ourstrategy/Project\%20Management/Documen ts/Other\%20PM\%20Resources/PMBOKGuideFourthEdition_protected.pdf (visited on April 14, 2016)

3. Simon, H. A.: Rational Choice and the Structure of the Environment, Psychological Review, vol.63, no. 2, pp. 129-138 (1956)

4. Keynes, J. M.: The General Theory of Employment, Interest and Money, Palgrave Macmillan (1936)

5. Fukuda, S., Maeda, A., Kimura, M.: Development of an Expert System for Weld Design Support, Trans. JSME (A), vol.52, no.476, pp.1183-1190 (1986) (in Japanese)

6. This system was awarded by Okada Memorial Foundation, (1986)

7. The development of this system led to Lifetime Achievement Award, ASME CIE Division in 2015

8. Securing the Future of German Manufacturing Industry Recommendations fr Implementing the Strategic Initiative INDUSTRIE 4.0 - Final Report of Industrie 4.0 Working Group

http://www.acatech.de/fileadmin/user_upload/Baumstruktur_nach_Website/Acat ech/root/de/Material fuer_Sonderseiten/Industrie 4.0/Final_report_Industrie 4. $\underline{0 \text { accessible.pdf (visited on April 14, 2016) }}$ 